\title{
Entre la cultura de masas y la alta cultura: Ricardo Piglia y La Argentina en pedazos
}

\section{Between media culture and high culture: Ricardo Piglia and La Argentina en pedazos}

\author{
Alfonso Macedo Rodríguez \\ Universidad Autónoma Metropolitana-Iztapalapa \\ alfonsomacedo@hotmail.com
}

Resumen: Las relaciones que el escritor argentino Ricardo Piglia mantuvo con los medios de comunicación y la cultura de masas han sido parcialmente documentadas pero siempre han sido visibles: desde sus clases sobre la novela argentina y Borges en la televisión cultural, sus guiones de cine y su narrativa, en la que ha creado obras a caballo entre el género policial, la ciencia ficción y el fantástico, pasando por sus experimentos con diversas formas - como la novela gráfica y la historieta que aún siguen siendo consideradas extraliterarias-, ha abierto nuevos caminos de recepción de su obra y la de los autores de la tradición literaria que ha analizado en sus novelas, ensayos y notas de diario. Así, y a pesar de la complejidad que supone la lectura atenta de su narrativa, sus intervenciones en los circuitos masivos no hacen concesiones a un público no especializado con los estudios literarios pero al mismo tiempo lo acerca a la lectura de Borges, Leopoldo Marechal, Manuel Puig o Roberto Artl, por ejemplo. El presente artículo analiza la relación de Piglia con La Argentina en pedazos (I993a), obra publicada de manera fragmentaria en la revista Fierro a partir de I984, y se detiene, en par- 
ticular, en las adaptaciones de algunas obras centrales de la literatura argentina: "El matadero" de Esteban Echeverría, "Las puertas del cielo" de Julio Cortázar y Los lanzallamas de Arlt. Los textos estudiados por Piglia para La Argentina en pedazos sugieren, indirectamente, una nueva revisión de la tradición literaria; simultáneamente, el encuentro entre dos manifestaciones culturales aparentemente antagónicas forma parte de una operación estética y política que fomenta la renovación artística y denuncia la violencia de Estado producida en la Argentina desde sus inicios como nación independiente.

Palabras clave: Ricardo Piglia, cultura de masas, alta cultura, historieta, La Argentina en pedazos.

Abstract: The relations that argentine writer Ricardo Piglia maintained with the media and mass culture have been partially documented but have always been visible: from his classes on the Argentine novel and Borges on cultural television, film scripts and his narrative work in which he has created works between the police genre, science fiction and fantasy, passing by its proximity to other forms considered extraliterary, such as graphic novel and comic, has opened new ways of receiving his own work and that of the authors of the literary tradition that he has analyzed in his novels, essays and journal notes. Thus, and despite the enormous complexity of attentive reading of his narrative, his interventions in the mass circuits do not make concessions to a non-specialized public with literary studies but at the same time brings him closer to reading Borges, Leopoldo Marechal, Manuel Puig o Roberto Artl, for example. This paper analyzes Piglia's relationship with the volume La Argentina en pedazos (1993a), a work that was published in a fragmentary and periodic way in Fierro magazine since 1984, and stops in particular in the cartoon versions of some works centrals of argentine literature, such as Esteban Echeverría's "El matadero", Cortázar’s "Las puertas del cielo" and Arlt's Los lanzallamas. The texts selected and studied by Piglia 
for La Argentina en pedazos suggest, indirectly, the review that the argentine writer makes of his literary tradition; simultaneously, the encounter between two seemingly antagonistic cultural manifestations is part of an aesthetic and political operation that encourages artistic renewal and denounces the violence of the State produced in Argentina since its foundation as an independent nation.

Keywords: Ricardo Piglia, Media culture, High culture, Comic, La Argentina en pedazos.

Recibido: 3 I de enero de $202 \mathrm{I}$

Aceptado: I de marzo de $202 \mathrm{I}$ https://dx.doi.org/IO.I 5 I74/rv.vi 3i28.526

¿Qué es la cultura de masas? Es la combinación de los canales de televisión y los grandes diarios que, al mismo tiempo, son los dueños de las editoriales. Ésa es la situación, creo, y ahi hay que actuar, como diría Brecht.

Ricardo Piglia, CRítica Y FiCCión.

Docos autores pueden mantener un diálogo constante y produc1 tivo entre las manifestaciones de la alta cultura y las expresiones de la cultura de masas como Ricardo Piglia (1941-2017). El cine, la televisión y la prensa se convirtieron, desde su formación de escritor, en una parte fundamental de su poética de ruptura, en la que siempre se propuso el rechazo y la crítica a los procedimientos convencionales de los medios de comunicación: a través de sus intervenciones en los mismos medios que cuestionaba -como los periódicos o las entrevistas transmitidas en televisión- atacó, casi 
de manera sistemática, la mercadotecnia de la industria cultural, lo que no le impidió participar, a su modo, en esta, siempre tomando distancia por medio de la ironía.

En los años sesenta, la joven generación de escritores a la que Piglia perteneció -y en la que también pueden mencionarse los nombres de Puig y Juan José Saer- comprendió perfectamente su lugar en la literatura: la asimilación de los escritores latinoamericanos más visibles y mediáticos a las estrategias del mercado literario produjo que esa generación tomara distancia y creara sus proyectos artísticos al margen de los modos convencionales en que la cultura fue divulgada y domesticada. Un comentario sobre el suicidio de José María Arguedas, escrito en su diario de 1969, confirma el lugar en el que buscaba situarse con respecto a las relaciones entre literatura y mercado: "También su muerte es una metáfora del escritor latinoamericano oculto, no revelado, subterráneo y opuesto a las marquesinas del boom" (Piglia, 2015: 167).

Piglia pensó de manera muy concreta en los procedimientos por los cuales sus obras podían intervenir (o dejar de hacerlo) en los medios y las estrategias de la industria cultural. Su relación con aquellos fue menos radical si se le compara con Saer-quien siempre mantuvo una posición más beligerante contra los medios y los escritores del Boom-; parte de su crítica a la industria cultural no proviene del lugar común del escritor convencional al sentirse superior a la cultura de masas, sino de una posición marxista en la que identifica rasgos clasistas entre los intelectuales. En ese sentido, asumió una severa postura crítica contra Sur, el grupo de Victoria Ocampo de donde surgió la revista homónima y en la que Borges intervino frecuentemente. Por eso, en parte, el proyecto narrativo de Roberto Arlt es reivindicado por Piglia en sus novelas y ensayos, en donde recupera lo bajo y lo grotesco del estilo del autor de $E l$ juguete rabioso como una forma de provocar a los escritores del "buen decir". En entrevista con Marco Antonio Campos, establece 
relaciones entre su poética y la narrativa de Arlt, a propósito de la cultura de masas y lo bajo:

El otro elemento muy importante en mi relación con Arlt es la oralidad. No de una forma lexical, sino más ligada con los ritmos, los tonos y la sintaxis. Al mismo tiempo, al lado de esto, hace una operación interesantísima: toma lo literario de traducciones españolas. Eso es lo que él creía que era la literatura. Por eso su lectura nos resulta extraña: de un lado, la zona de las voces de Buenos Aires; del otro, la alta literatura, que en él, se halla en la lectura de las malas traducciones que hacían los españoles (Piglia, 1999: 173).

Uno de los vínculos que une la escritura de Piglia con la de su predecesor Arlt es el complot ${ }^{1}$ lingüístico y político que dirige sus baterías contra la burguesía y los intelectuales cercanos al capitalismo. En la entrevista citada, las respuestas de Piglia establecen relaciones entre sus propias novelas y las de Arlt; Campos se interesa en cómo el personaje Emilio Renzi coloca a Arlt por encima de Borges en Respiración artificial. Como programa literario, se trata de recuperar lo marginal como una forma de analizar el canon vigente de los ańos setenta y ochenta-que comenzó a transformarse a partir de la publicación de la primera novela de Piglia-, siempre desde un ángulo marxista heterodoxo que denuncia el poder de la

${ }^{1}$ En "Teoría del complot", Piglia afirma: "En principio, el complot supone una conjura y es ilegal porque es secreto; su amenaza implícita no debe atribuirse a la simple peligrosidad de sus métodos sino al carácter clandestino de su organización. Como política, postula la secta, la infiltración, la invisibilidad" (Piglia, 2014: 99). En este texto, además, vuelve a señalar a Arlt como el máximo novelista del complot en la Argentina con Los siete locos: "Aunque ha sido leída como la novela de Erdosain, creo que la que tiene un lugar central es la novela del Astrólogo, la construcción de un gran complot con los siete locos como conspiradores. Y es alrededor de la noción de maquinación que la novela constituye su eficacia (101). 
clase intelectual y la dictadura militar de finales de la década de los setenta y principios de la siguiente.

Esta crítica a las obras y posturas de los intelectuales de las generaciones pasadas que exhibían ciertas pretensiones aristocráticas (Victoria Ocampo, Bioy Casares, Borges, Cortázar: todos antiperonistas) se complementa con la reivindicación del autor de $E l j u$ guete rabioso, siempre asociado a la baja cultura, lo marginal y a lo que fue considerado subliteratura: la historieta, de origen masivo pero cuyas técnicas narrativas, en parte tomadas del cine, contribuyeron a superar las formas canónicas de la literatura occidental culta; no es gratuito, así, que Piglia establezca una relación inédita entre las novelas de Roberto Arlt y los cómics, ya que ambos géneros fueron considerados "literaturas menores" (Gutiérrez, 2009) o marginales:

Quiero decir que la tradición de la literatura argentina como lo mismo se podía decir de la literatura de Roberto Arlt, esta relación con géneros considerados menores por la alta cultura y etc., es una tradición muy fuerte y en mi caso me he manejado con absoluta fluidez, he escrito guiones de cine, he trabajado en revistas de historietas, he dirigido la primera colección de literatura policial norteamericana que se hizo en español, "La serie negra" que comencé a publicar en el '68, antes de que los españoles empezaran a publicar también el género. Quiero decir que para mí fue muy natural la idea de que los géneros se cruzan y se intercambian y la historieta es por supuesto uno de los referentes, me parece a mí, de la cultura contemporánea (Gutiérrez, 2009).

Así, reconoce la tendencia, propia de los escritores de los sesenta y setenta, de intervenir desde adentro contra los medios de comunicación, ya que resultaba inevitable, después del Boom, mantenerse ajeno a aquellos. Justamente, su libro de clases de literatura 
Las tres vanguardias abre con una introducción a los procedimientos artísticos de los que su generación se apropió y exploró para hacer una oposición estética y política a los medios de comunicación y la industria cultural: Rodolfo Walsh, Manuel Puig y Juan José Saer son estudiados a partir de sus poéticas en relación con la cultura popular: "Hay que considerar, por lo tanto, la relación entre novela y medios de masas" (Piglia, 2016: 17). Para los cuatro escritores esa relación es ineludible, por lo que crearon sus proyectos literarios enfrentando a los medios de comunicación pero también apropiándose de sus recursos y asimilando algunos de sus procedimientos para producir nuevas significaciones. ${ }^{2}$

Esa relación de la cultura de masas con las novelas de largo aliento, los textos reflexivos (ensayos, discursos, notas de diario, prólogos) y las narraciones breves establece una suerte de bilocación en la que nuestro escritor se mueve sin hacer concesiones a los lectores -como lo dice de modo explícito- ni menospreciar cualquier manifestación de las que aún son consideradas artes menores: comentarios de series de televisión, clases de literatura en el canal nacional TVP, entrevistas transmitidas por YouTube, notas de diario para el suplemento Babelia de El País de España y Revista $\tilde{N}$ del diario Clarín de Argentina, participación como guionista en filmes de ficción y documentales, acercamiento a la historieta y la

${ }^{2}$ En una larga conversación fechada en 2010, Piglia explica la relación de los tres autores (las tres vanguardias argentinas de la segunda mitad del siglo xx) con los medios de comunicación y los modos en que, dentro de sus obras, responden a esa omnipresencia: "Saer construye una poética de antagonismo directo. La literatura es una lengua lo suficientemente hermética para no ser cooptada por el discurso trivial de los medios de masas. Después estaría Puig, quien es el gran renovador en este punto, que negocia con la cultura de masas como forma. Porque las novelas de Puig son muy experimentales, no es que él escribe novelas de masas, él trabaja los discursos de masas. Y Walsh, que me parece muy actual, que actúa sobre los medios de masas, inventa periódicos" (Piglia, 2015b: 142). 
novela gráfica, etc. ${ }^{3}$ Sin perder sus complejos registros escriturarios ni "rebajar" su poética a los esquemas rigurosos de los medios masivos, Piglia supo intervenir en estos y logró suscitar nuevos espacios de reflexión estética y política en diálogo con la tradición literaria argentina: "De lo que más me ha gustado realizar es una suerte de sección que hice en una muy buena revista de historietas (Fierro), que era una suerte de antología de la literatura argentina. Los muchachos hacían la historieta y yo escribía el texto. Las mías han sido más esas intervenciones laterales a lo que sería el camino central de la crítica académica” (Piglia, 1999: 193).

\section{La tradición literaria argentina en el cómic: La Argentina en pedazos}

El texto que escribia acompañando era un texto que escribia sin hacer ninguna concesión, en el mal sentido, al público, escribia mis ideas sobre literatura argentina obedeciendo a ciertos registros de la escritura crítica que son los que a mi me interesan, polémico y claro, en lo posible, escribia mis ideas criticas para un público que normalmente está ajeno a la circulación y la sección tuvo una repercusión muy notoria tanto que después se publicó un libro y por ejemplo en los co-

${ }^{3}$ Cfr. "Ensayo, autobiografía y nuevas artes: de Alfonso Reyes a Ricardo Piglia" (Macedo, 2017: 431-447), donde se parte de una reflexión sobre literatura y nuevas artes (nuevos medios de comunicación), y "Relaciones intertextuales: los caminos de la literatura en las series televisivas. Breaking Bad y True Detective" (Macedo Rodríguez, 2018: 85-108), cuya introducción analiza la actualidad de los medios -particularmente del cine y las series de televisión- a partir de las posturas de Piglia y Saer. 
legios secundarios era habitual que los profesores usaran la revista Fierro para enseñar literatura argentina usando la sección y discutiendo algunos de los textos que estaban, de Quiroga, de Arlt, en el colegio.

Ricardo Piglia en entrevista con Rafael Gutiérrez

En 1993, Ricardo Piglia publica La Argentina en pedazos, un libro híbrido que combinó la crítica literaria con el ensayo y el género prólogo al tiempo que se colocó en las fronteras del lenguaje gráfico y la escritura. Se trata de una serie de relatos representados bajo el código del cómic que recupera algunas de las grandes narraciones -ordenados no cronológica sino arbitrariamente, aunque los relatos inicial y final tienen una intencionalidad evidente al ser ubicados en esos espacios tan precisos y significativos- de la historia literaria argentina y otros no tan famosos pero que se ajustan, parcialmente, al canon personal del antologista. Así, el lector conoce historietas adaptadas -que, desde luego, siempre pueden ser leídas de manera independiente del texto original- de "El matadero" de Esteban Echeverría, "Un fenómeno inexplicable" de Leopoldo Lugones, "Historia del guerrero y de la cautiva" de Borges, "Las puertas del cielo" de Julio Cortázar, un fragmento de Los lanzallamas de Roberto Arlt, otro de Boquitas pintadas de Manuel Puig, otro de Los dueños de la tierra de David Viñas y la adaptación al cómic de la letra del tango "La Gayola" de Tuegols y Taggini, entre otras.

Los ensayos están divididos en pequeñas secciones; también pueden ser leídos como si fueran las notas en un diario que Piglia publicó en los últimos ańos de su vida. No es casual que haya copiado y pegado párrafos enteros de algunos de sus ensayos, como 
el dedicado a Arlt: se trata de una reelaboración de un ensayo de los años setenta. ${ }^{4}$

La violencia es el tema central: cruza la tradición literaria de su país. Precisamente, la publicación de las adaptaciones al cómic tuvo lugar en el seno de la revista Fierro, surgida en el periodo posdictatorial (en 1984) como una forma de denunciar los crímenes de Estado durante la etapa militar que había concluido un año antes: "Se trataba de un original proyecto editorial surgido como uno de los productos culturales que acompańaron el retorno de la democracia a la Argentina. La revista se presentaba con el subtítulo 'Historieta para sobrevivientes', haciendo referencia tanto a sus creadores como a sus lectores, aquellos que habían sobrevivido al "Proceso"' (Gutiérrez, 2009). En su texto "Mandrini, Piglia y la historieta", Rafael Gutiérrez sostiene que La Argentina en pedazos salió a la luz con Ricardo Piglia como el único autor debido a criterios comerciales, como una "maniobra editorial" (2009). Incluso, en entrevista, Piglia señala a Juan Sasturain como el autor del nombre de la sección "La Argentina en pedazos", título polisémico que aludía "a la fragmentación que nosotros, básicamente el tema que íbamos a trabajar la presencia de la violencia en la literatura argentina en distintos momentos y a través de estos sistemas de fragmentación que suponían adaptaciones de textos y al mismo tiempo 'La Argentina de pedazos' aludía a la situación de la Argentina que acababa de salir de la dictadura militar" (Gutiérrez, 2009).

Gutiérrez afirma que la obra mantiene la disposición textual de las adaptaciones, tal como aparecieron originalmente en la revista, incluyendo los textos introductorios de Piglia. De este modo, una

${ }^{4}$ Cfr. "Roberto Arlt. La ficción del dinero" (Piglia, 1993a: 124-126) con "Roberto Arlt: la ficción del dinero" (Piglia, 2000: 806-809). El título es muy parecido y las ideas son las mismas, aunque en el primer caso aparezcan bajo la forma del microensayo y en el segundo la escritura ensayística sea convencional. 
revisión del índice del volumen muestra una diferencia importante entre los dos primeros textos y el resto: en los dos primeros ("El matadero" de Echeverría y el fragmento de la novela de Viñas) no aparece el nombre del adaptador y solo se da reconocimiento a los dibujantes. A partir de la tercera historieta ya se señala el nombre de quien la adaptó, ${ }^{5}$ lo que puede sugerir que las dos primeras adaptaciones fueron realizadas por el propio Piglia, quien afirma que el primer texto adaptado al cómic fue el de Echeverría (Gutiérrez, 2009). También cabe la posibilidad de que fuera Sasturain el adaptador de los textos ya que, con el dibujante Enrique Breccia, integró una dupla fundamental en el campo de la historieta argentina: las ilustraciones de las tres primeras adaptaciones corrieron a cargo del segundo. ${ }^{6}$

El volumen abre con "El matadero", uno de los primeros cuentos en la historia de la literatura hispanoamericana. Esta primera adaptación, que de inmediato remite a la Generación del 37, produce una serie de asociaciones que va de lo literario a lo político en torno a la dictadura de Juan Manuel de Rosas; de este modo, la operación artística de Sasturain, Breccia y Piglia consiste en sugerir la repetición de la represión del Estado contra los ciudadanos, sea en el siglo XIX, sea a finales del siglo Xx. ${ }^{7}$ Así, "El matadero", consi-

${ }^{5}$ Los adaptadores son: Norberto Buscaglia (en cuatro ocasiones), Otto Carlos Miller, Carlos Trillo, Eugenio Mandrini, Manuel Aranda y José Muñoz.

${ }^{6}$ La labor editorial en conjunto de Sasturain y Breccia tuvo su consolidación no solo en estos números iniciales, sino también en la publicación de la historieta Perramus, "un alucinado recorrido por la dictadura y su problematización de la memoria" (Pérez del Solar, 2011: 60), lo que sugiere el modo en que el periodo posdictatorial es representado en la ficción gráfica de aquellos años. Por otra parte, el artículo de Pérez del Solar es uno de los pocos que estudian La Argentina en pedazos como conjunto a partir del análisis de los temas y las formas $\mathrm{y}$, sobre todo, la relación entre el texto original y la adaptación.

${ }^{7}$ No está de más recordar que Respiración artificial, la primera novela de Piglia publicada en 1980 -cuando a los militares aún les faltaba tres ańos para retirarse 
derado también como uno de los textos fundadores de las letras argentinas (Laiseca, 2009: 320), funciona como una alegoría de otro régimen atroz: el de la dictadura militar que controló brutalmente al país entre 1976 y 1983; desde una perspectiva que estudie lo intertextual, también pueden establecerse diversas relaciones entre las obras seleccionadas para el género historieta y las dos primeras novelas de Piglia: Respiración artificial y La ciudad ausente (1992). ${ }^{8}$

En una breve reseña que celebraba la aparición del libro, Graciela Speranza analiza su estructura a través de un pequeño acercamiento a la versión en cómic del cuento de Echeverría:

La Argentina en pedazos es una versión curiosa de una tradición que se inicia en "El matadero", nuestro primer cuento: la historia de la violencia argentina a través de la ficción, el uso político del relato de una cultura de mezcla. El título, si se quiere, refiere a la doble naturaleza del libro. Por un lado, los cuadros de la historieta que componen a su modo imágenes disgregadas en la ficción. Por otro, los prólogos de Ricardo Piglia, que organizan en la lectura fragmentos dispersos de esa tradición. Por detrás se perfila aquello que inspira el conjunto: la Argentina en pedazos, "esa figura de país que alucinan los escritores a contraluz de la historia 'verdadera’, como su pesadilla" (Speranza, 2000: 270).

del poder-, establece una serie de relaciones entre ciertos sucesos históricos y ficcionales ocurridos durante el gobierno de Rosas y una serie de acciones de disidentes de la dictadura militar del último cuarto del siglo xx.

${ }^{8}$ La Argentina en pedazos se publicó diez años después del fin del periodo militar. Un año antes, Piglia había publicado La ciudad ausente en la que, implícitamente, cuestiona las leyes de Obediencia y Punto Final que el nuevo gobierno civil había impulsado para no enjuiciar a los militares. Esta novela tuvo una primera adaptación al cómic en 2000 y una segunda edición con nuevas viñetas (Piglia, 2008), lo que permite continuar el estudio de la trayectoria iniciada con $\mathrm{La}$ Argentina en pedazos a propósito de los modos en que Piglia interviene en los medios de comunicación y la industria cultural. 
Como contraste ante la observación de Pérez del Solar sobre la subordinación de las historietas a los ensayos de Piglia (Pérez del Solar, 2011: 61), en la apreciación de Speranza, escritura e imagen coinciden plenamente y establecen un signo dual cuyos significantes y significados remiten a las numerosas dictaduras, las problemáticas sociales, el exterminio de los indios, el poder de la oligarquía y la educación sentimental en tiempos de la cultura de masas.

En la presentación del cuento fundador de la literatura argentina, Piglia vuelve al tópico civilización/barbarie - no sin referirse al Facundo de Sarmiento, el otro gran pilar (Piglia, 1993a: 8-9)- a través de la representación del discurso de los carniceros, seguidores del dictador Rosas, y del discurso del opositor que muere en manos de aquéllos: como Speranza sostiene, la conciliación de lo cosmopolita con lo popular y grotesco es el inicio de una tradición que reúne lo culto y lo vulgar en una misma obra, lejos del canon aristotélico de la belleza (2000: 270): en las vińetas, los closeups a los carniceros -representantes extraoficiales del poder del dictador- y sus giros verbales, en los que abundan los signos de exclamación, tal como queda de manifiesto en los globos de la historieta que representan sus diálogos y su encuentro con el unitario, contrastan con la aparición del refinado opositor a Rosas: en medio de la algarabía producida por la matanza de las reses que pondrá fin a la prohibición del consumo de carne en plena cuaresma, los partidarios de Rosas lo ven a lo lejos: aparece montando a caballo "en silla, como los gringos" (Piglia, 1993a: 15), totalmente despreocupado. Un aporte estilístico gráfico que se distingue en esta primera historieta es la representación del discurso del unitario, con un hipérbaton incluido y una elegante letra cursiva que lo diferencia de los representantes de la barbarie y sus registros orales populares: "Infames sayones, ¿qué intentan hacer de mí?" (Piglia, 1993a: 16). También se trata de una caligrafía proveniente de la alta cultura que puede asociarse con una práctica femenina en oposición a las 
palabras de los ejecutores extraoficiales de Rosas; finalmente, otra lectura subraya "la incapacidad del unitario por hacerse entender por los otros; su problema es también el de hacer inteligible su discurso (en clave de historieta: hacerlo legible)" (Pérez del Solar, 2011: 74).

La gran diferencia visual entre la alta cultura, de raíz europea y romántica, y la cultura popular, representada por los criollos al servicio del Restaurador, es física pero, sobre todo, gráfica y gramatical. Desde luego, la paradoja de la civilización como instauradora del progreso y el bienestar es cuestionada por los intelectuales posteriores a la generación del 37; en Respiración artificial, Piglia propone una revisión de la dictadura rosista a la luz de los crímenes de Estado durante el periodo del Proceso de Reorganización Nacional y en el contexto de la migración de las ideas del nazismo a los cuerpos militares argentinos desde los tiempos de Perón.

La versión en historieta de "El matadero" también funciona como una forma de analizar los procedimientos de Piglia para intervenir en los medios masivos y, desde ahí, sugerir una nueva revisión del canon, al que incorpora el ensayo dedicado a "La gallina degollada" del escritor uruguayo Horacio Quiroga. No se trata solamente de promover el diálogo transmediático entre los soportes tradicionales de la literatura con los lenguajes gráficos o promover la lectura de los textos nacionales, sino de hacer una valoración de la tradición argentina y juzgar su pertinencia y actualidad. Así, en sus ensayos, no todos los escritores seleccionados salen bien librados; tal es el caso de Cortázar, el representante argentino del Boom que produjo, según Piglia, la unión entre mercado, medios y literatura:

Algún día habrá que hacer el catálogo de los nombres, los lugares y las marcas que circulan por los textos de Cortázar; ese repertorio dibujará, sin duda, los rastros de una compulsión y dejará ver 
hasta qué punto su obra ha sido siempre fiel a esa pasión avara de apropiarse de la realidad a través del mercado. Desde esta perspectiva la obra de Cortázar puede ser leída como una épica del consumo o, mejor, como la aventura de un explorador experimentado y sagaz que trata de dejar su huella en la selva indiscriminada del mercado capitalista (Piglia, 1993a: 40).

El título del fragmento citado se llama "Marcas" y puede ser leído con una doble significación: por un lado, el sentido evidente de la palabra sugiere señales, indicios de una constante cortazariana; por otro, de manera más sutil, se trataría del universo de las marcas comerciales en la que el nombre Julio Cortázar -como el de Salvador Dalí- es un sello de garantía para los lectores-consumidores de clase media y clase alta.'

El dictamen negativo de la obra de Cortázar también tiene relación con su supuesta visión clasista y racista detectada en cuentos como "Las puertas del cielo", texto "reaccionario [...] de antiperonista blanco", como confiesa (Piglia, 1993a: 41): el ensayo que antecede a la versión en cómic funciona para tomar distancia de la poética cortazariana por su cercanía con los medios y por mantener una posición clasista, o sea la posición de un tipo de intelectual que se considera superior al pueblo y rechaza abiertamente sus preferencias políticas -a las que considera populistas. Los “cabecitas negras" ${ }^{10}$ o monstruos caricaturizados en el relato de Cortázar

9 Para el estudio de la perspectiva que Piglia tuvo de la figura de Cortázar, cfr. Macedo (2012: 157-167).

10 "Cabecita negra" de Germán Rozenmacher también fue adaptado al cómic para Fierro. En la presentación, Piglia lo relaciona con "Casa tomada" y otros cuentos de Cortázar pero, a diferencia de "Las puertas del cielo", lo lee como una denuncia contra el clasismo y el racismo de la burguesía argentina: “'Cabecita negra' puede considerarse una versión irónica de 'Casa tomada' de Julio Cortázar. O mejor como una versión del comentario de Sebreli al cuento de 
muestran no solo sus prejuicios de clase, también sugieren que el público masivo del autor es la clase media que, en el fondo y secretamente, sigue aspirando a la clase alta.

En la historieta "Las puertas del cielo", resulta evidente el contraste entre el doctor Marcelo, narrador de la historia, y sus amigos de juerga, a quienes analiza como si se tratara de un antropólogo inmerso en la cultura popular. La adaptación de Norberto Buscaglia y los dibujos de Carlos Nine hacen visible la línea crítica sugerida con anticipación por Piglia: con un aire de familia que remite al joven Cortázar de los cuarenta y cincuenta, Marcelo aparece ligeramente aislado de todos, observando a la pareja que baila y aprecia, no sin hacer notar su desprecio por las masas que se concentran en el tugurio del barrio de Palermo (Piglia, 1993a: 44). El acontecimiento fantástico narrado en el texto original ocurre cuando la mujer, que había muerto recientemente, vuelve unos minutos de la muerte para seguir bailando mientras el narrador documenta ese fugaz intento del amigo en busca de su amada, al pie de las puertas del cielo que rápidamente vuelven a cerrarse: “SABÍA QUE PERDÍA EL TIEMPO, SABÍA QUE VOLVERÍA AGOBIADO Y SEDIENTO SIN HABER ENCONTRADO LAS PUERTAS DEL CIELO ENTRE ESE HUMO Y esa Gente” (Piglia, 1993a: 51). En la viñeta final de la narración cuyo discurso es asumido plenamente por el narrador personaje, ya no aparece el dibujo del joven y rasurado doctor Marcelo, sino el del escritor Julio Cortázar que, con barba espesa

Cortázar. 'Casa tomada expresa fantásticamente esa angustiosa sensación de invasión que el cabecita negra provoca en la clase media'. La interpretación de Sebreli define mejor a Sebreli que al cuento de Cortázar pero de todos modos se ha convertido en un lugar común de la crítica y se superpone con el cuento mismo" (Piglia, 1993a: 91). 
y cigarrillo en los labios, rememora el fugaz encuentro fantástico que tuvo lugar muchos ańos antes y del que fue el único testigo. ${ }^{11}$

La última historieta que aquí se analizará es un fragmento de Los lanzallamas (1931) de Roberto Arlt, obra que cierra el volumen. Se trata de la muerte de un personaje icónico de Los siete locos: Haffner, el Rufián Melancólico. Al terminar La Argentina en pedazos con una obra emblemática de Arlt, Piglia lo sitúa en el extremo contrario de Cortázar: esta operación de curaduría ${ }^{12}$ hace explícita su poética de lo marginal y subversivo:

${ }^{11}$ Cabe anotar que, en las representaciones de los personajes de estas historietas y en la novela gráfica La ciudad ausente, se confunden las nociones de autor, narrador y personaje al ser yuxtapuestas en una sola entidad, como el caso de Cortázar, pero también como el de un Borges narrador que asume el relato de manera directa en la versión gráfica de "Historia del guerrero y de la cautiva", sin intermediario (Piglia, 1993a: 108 y 113). En cuanto a Piglia, cuando en la novela gráfica La ciudad ausente se dibuja a su alter ego Emilio Renzi, se recurre a los rasgos físicos del escritor argentino (Piglia, 2008: 16). Un caso más, el primero, es Héctor Germán Oesterheld en El Eternauta, novela de ciencia ficción por entregas de la década de los cincuenta que posee una estructura metaficcional cuya función narrativa consiste en darle una apariencia de verosimilitud al relato: el escritor H. G. Oesterheld recibe a un visitante del futuro que narra y advierte sobre una inminente invasión extraterrestre en Buenos Aires (Oesterheld, 2013: 1). Por su parte, Pérez del Solar sostiene que la representación gráfica de Cortázar y Borges como autores y narradores se debe a su presencia mediática: "se han convertido en escritores canónicos e íconos de la cultura de masas" (2011: 83). Desde mi perspectiva, esta incorporación puede ser leída como una crítica al clasismo en el caso de Cortázar y como una representación que intenta fijar la "expresión de la irrealidad" - para emplear el concepto emblemático de Ana María Barrenechea- en el caso de Borges y sus cuentos fantásticos.

${ }^{12}$ Como Borges y Bioy en sus antologías, Piglia construye proyectos que niegan o cuestionan su propia selección, lo que puede considerarse como un giro de su poética; así, incorpora a Horacio Quiroga como si fuera argentino y analiza una letra de tango de Armando Taggini que también emigra al cómic. En cuanto a la figura de Arlt, otra antología, dedicada al cuento policial y preparada por Piglia en la misma época, inicia con "Las fieras", cuento de El jorobadito que le 
Las novelas de Arlt son extrañas utopías, negativas y crueles, que se alimentan del presente, quiero decir, de nuestra actualidad. Sus textos hacen pensar en esa forma tan moderna de ficción especulativa tipo Philip Dick con quien, por supuesto, tiene muchos puntos en común. La escritura de Arlt se instala en el porvenir, trabaja lo que todavía no es: parece que siempre estuviera escribiendo sobre la Argentina de hoy. Arlt supo captar el centro paranoico de esa sociedad. Sus novelas manejan lo social como conspiración, como guerra; el poder como una máquina perversa y ficcional. Arlt narró las intrigas que sostienen las redes de dominación en la Argentina moderna (Piglia, 1993a: 124).

La lectura de Piglia sobre la narrativa arltiana es su modo más directo y efectivo para establecer relaciones genealógicas: la tradición literaria rioplatense pasa por Arlt, Borges, Macedonio Fernández y aterriza en Piglia y La ciudad ausente; el ambiente hostil, paranoico y represivo flota pesadamente en las imágenes de la muerte de Haffner, un aspecto que, desde el código escrito de la novela original y la historieta, se recupera de manera abierta para establecer esa genealogía.

Haffner ha invertido una gran cantidad de dinero en el proyecto delirante del Astrólogo, quien en Los siete locos, la primera parte del díptico novelístico, se ha propuesto la creación de una

da título a la recopilación. De este modo, Piglia reordena la tradición argentina y coloca en el centro a un escritor considerado marginal por los mismos círculos de escritores (Borges, Güiraldes, Sábato) (Piglia, 1993b). Finalmente, en esos giros inesperados característicos de las antologías de Borges y Piglia, este, en 2001, agregó la gran historieta argentina a su colección de clásicos de literatura para la Biblioteca Clarín: "me parecía natural incluir allí El Eternauta como un texto clásico de la literatura argentina o de la cultura argentina" (Gutiérrez, 2009). 
sociedad secreta que ponga de rodillas a la ciudad de Buenos Aires. Mediante el subsidio otorgado por Haffner, quien con su sistema de prostíbulos desmontará la economía capitalista una vez que se paralice a causa de las acciones terroristas programadas, el Astrólogo y la sociedad secreta tomarán el poder. Sin embargo, el proyecto fracasa desde el principio y Haffner cae en una emboscada creada por sus enemigos prostibularios, quienes lo ejecutan por la espalda.

A pesar de la visión cínica de la vida de este "filósofo utópico y economista vulgar" (Piglia, 1993a: 126), Haffner calla los nombres de sus asesinos y "morirá en su ley" (Arlt, 2000: 399) sin ceder a la tortura de la policía que busca un pretexto para detener a otros criminales que, paradójicamente, son protegidos por el sistema (Piglia, 1993a: 136)..$^{13}$

En la agonía, el Rufián Melancólico, cuyo sobrenombre se debe a su oficio de padrote con intermitentes crisis de arrepentimiento, mantiene el silencio y se concentra en los recuerdos de las mujeres maltratadas a quienes puso en la calle para que le dieran ganancias. Empleando el claroscuro como una técnica en la que siempre aparece un fondo negro con imágenes a contraluz y rasgos expresionistas en los rostros alargados y desamparados, la representación gráfica de este episodio de Los lanzallamas expresa las contradicciones del capitalismo de las primeras décadas del siglo xx, tan cercano al sistema neoliberal de los años noventa del mismo siglo, cuando se había cumplido una década del fin del gobierno dictatorial.

${ }^{13}$ La adaptación de Los siete locos y Los lanzallamas a la televisión argentina en 2015 tuvo en Piglia al jefe del equipo de guionistas, por lo que podemos atribuirle el argumento; ahí se revela un cambio fundamental: Haffner es asesinado por el Hombre que vio a la Partera bajo la orden del Astrólogo, lo que pone en evidencia el carácter verdaderamente destructor de este personaje, quien siembra el caos a su paso y desaparece sin dejar rastro para reaparecer en el cuento "El Astrólogo" de Piglia (Piglia, 2014: 185-198; 2018: 35-49). 


\section{Conclusión. La función social de la historieta en la tradición literaria argentina}

Desde sus orígenes, la tradición literaria argentina se conformó por su ambivalencia temática y formal: de la oposición inaugural entre los conceptos de civilización y barbarie en "El matadero" y Facundo, pasando por el empleo de un lenguaje popular en oposición al lenguaje culto de las élites intelectuales (Arlt como escritor marginal en oposición a Leopoldo Lugones y Ricardo Güiraldes como escritores oficiales) hasta el empleo permanente de géneros y formas menores, como la novela de folletín -que remite a la estructura de las novelas de Manuel Puig y cuya novela Boquitas pintadas es incluida en La Argentina en pedazos con el relato del asesinato del amante de Mabel-, el género policial, la literatura fantástica y la ciencia ficción a finales del siglo xx. La ciudad ausente combina sagazmente estos tres géneros dentro de una vertiginosa estructura metaficcional que reúne la tradición argentina (urbana y rural, culta y popular).

La relación de La Argentina en pedazos con La ciudad ausente se produce no solo por las fechas de sus publicaciones (1993 y 1992, respectivamente), sino por su función política, ya que los objetivos de la revista Fierro, desde la caída del régimen militar, y la de los escritores e intelectuales como Piglia, consistió en hallar nuevas formas de expresión que contribuyeran a la renovación de la tradición dentro de un escenario político en el que la participación civil fuera fundamental. En el caso específico del autor de La ciudad ausente, los cruces que efectuó con algunas obras y géneros propios de la cultura de masas produjeron una denuncia social ante la violencia sistemática del Estado argentino (desde su fundación como nación soberana en el siglo XIX, con Juan Manuel de Rosas como el primer dictador, hasta la última dictadura cívico-militar) y una nueva revisión del canon que dejó de lado a los escritores 
oficiales para reivindicar a otros, como Macedonio Fernández y Roberto Arlt. Justamente, el director Fernando Spiner -con quien Piglia trabajó para la serie Los siete locos y Los lanzallamas (2015) en la televisión pública argentina- realizó un largometraje que inicialmente estaría basado en la novela, pero al final se filmó una historia alternativa: La sonámbula; otro acercamiento entre cultura de masas y alta cultura fue la adaptación de La ciudad ausente a la novela gráfica en 2000, lo que confirmó algunas constantes literarias y políticas de su autor (Piglia, 2008). Una de las imágenes finales de esta obra gráfica -en la que aparece Elena, la máquina de narrar- es un homenaje a Blade Runner de Ridley Scott (Piglia, 2008: 86): el gobierno (civil o militar) sigue ejerciendo el control.

La relación de Piglia con los medios y la cultura de masas no consiste en acercar demagógicamente la cultura al pueblo, se trata de establecer un diálogo entre los procedimientos artísticos de la alta cultura y la cultura de masas para producir nuevas significaciones que, en gran medida, cumplan una función estética y política. En relación con aquélla, Piglia, en La Argentina en pedazos, hace un nuevo repaso de la tradición argentina y vuelve a reivindicar a Arlt y Puig -los últimos autores de la serie-, cuestiona otra vez la obra y la figura de Cortázar por considerarla demasiado cercana a los medios (en un sentido clasista, burgués y consumista), reafirma la importancia de Borges dentro del canon y, ante todo, recupera algunos momentos en los que la alta cultura y la cultura de masas han establecido un vínculo único, como queda de manifiesto en su texto sobre el teatro de Armando Discépolo (hermano del compositor de tangos Enrique Santos Discépolo) y su análisis de las letras de tango (como "La gayola" de Tuegols y Taggini), que de paso remiten a las novelas de Puig; en sus ensayos-prólogos, Piglia realiza una operación subversiva al denunciar la violencia que se origina desde la época de la independencia. A partir de ahí, se establece 
una genealogía en que se documenta las acciones del Estado para controlar al pueblo mediante la tortura y la represión.

Más que educar, "cultivar" o instruir al "gran público", se trata de producir nuevos vínculos revolucionarios en los planos estético y político para remover el estancamiento reproducido por los medios de comunicación. Solo en diálogo permanente con todas las manifestaciones culturales habrá un proceso de desautomatización que permita la evolución artística.

\section{Bibliografía}

Arlt, Roberto, 2000, Los siete locos / Los lanzallamas, Mario Goloboff (ed.), Colección Archivos 44, Allca xx / Fondo de Cultura Económica / Université de París X, París.

Gutiérrez, Rafael, 2009, "Mandrini, Piglia y la historieta”. Disponible en: https://www.redalyc.org/articulo.oa?id=181714927018. (Consultado: 10/I/2020).

Laiseca, Alberto, 2009, "El matadero, de Esteban Echeverría”, en Sylvia Iparraguirre (coord.), La literatura argentina por escritores argentinos. Narradores, poetas y dramaturgos, Biblioteca Nacional, Buenos Aires, pp. 313-320.

Macedo Rodríguez, Alfonso, 2012, "Entre la negación y el homenaje: la mirada de Ricardo Piglia sobre Julio Cortázar”, en Literatura hispanoamericana: juegos y estrategias, Universidad Autónoma de Tlaxcala, Tlaxcala, pp. 157-167.

, 2017, "Ensayo, autobiografía y nuevas artes: de Alfonso Reyes a Ricardo Piglia”, en Liliana Weinberg (coord.), El ensayo en diálogo, vol. II, Centro de Investigaciones sobre América Latina y el Caribe / Universidad Nacional Autónoma de México, Ciudad de México, pp. 431-447. 
, 2018, "Relaciones intertextuales: los caminos de la literatura en las series televisivas Breaking Bad y True Detective", en Fernando Castańeda Sabido y Pablo Armando González Ulloa Aguirre (coords.), Reflexiones multidisciplinarias sobre metodologías actuales en las ciencias sociales, Universidad Nacional Autónoma de México / Ediciones La Biblioteca, México, pp. 85-108.

Oesterheld, Héctor Germán, y Francisco Solano López, 2013, El Eternauta, Juan Sasturain (pról.), RM, Ciudad de México.

Pérez del Solar, Pedro, 2011, "Los rostros de la violencia. Historietas en La Argentina en pedazos", Revista Iberoamericana, vol. LXXVII, núm. 234, enero-marzo, pp. 59-86.

Piglia, Ricardo, 1993a, La Argentina en pedazos, Ediciones de la Urraca, Colección Fierro, Buenos Aires. Aires. , 1993b, Las fieras (sel., y pról.), Clarín / Aguilar, Buenos

, 1999, Cuentos con dos rostros, Marco Antonio Campos (sel., y epílogo), Juan Villoro (pról.), Universidad Nacional Autónoma de México, Ciudad de México.

, 2000, "Roberto Arlt: la ficción del dinero", en Roberto Arlt, Los siete locos / Los lanzallamas, Mario Goloboff (ed.), Colección Archivos 44, Allca xx / Fondo de Cultura Económica / Université de París X, París, pp. 806-809.

,2001, Crítica y ficción, Anagrama, Barcelona.

, 2008, La ciudad ausente, Luis Scafati (ilustraciones), Pablo De Santis (pról., y adaptación), Libros del Zorro Rojo, Barcelona / Madrid.

, 2014, Antología personal, Fondo de Cultura Económica, Ciudad de México.

, 2015a, Los diarios de Emilio Renzi. Años de formación, Anagrama, Barcelona. 
,2015b, La forma inicial. Conversaciones en Princeton, Arcadio Díaz Quiñones y Paul Firbas (eds.), Sexto Piso, Ciudad de México / Madrid.

, 2016, Las tres vanguardias. Saer, Puig, Walsh, Patricia Somoza (ed.), Eterna Cadencia editora, Buenos Aires. , 2018, Los casos del comisario Croce, Anagrama, Barcelona.

Speranza, Graciela, 2000, [sin título], en Ricardo Piglia, Jorge Fornet (ed.), Casa de Las Américas, Serie Valoración Múltiple, Bogotá, pp. 270-271. 